\title{
Motivação docente: reflexões acerca do construto
}

\author{
Tárcia Rita Davoglio
}

\author{
Bettina Steren dos Santos
}

\begin{abstract}
RESUMO: Este ensaio reflexivo visa problematizar a conceituação, a descrição e a pesquisa da motivação docente, defendendo a necessidade de compreender a motivação como um construto que, embora complexo e multifacetado, demanda por clareza conceitual e epistemológica, além de definição semântica e operacional em sua aplicação nas pesquisas empíricas no âmbito da Educação. Propõese, em última análise, a oferecer subsídios para a promoção do debate profícuo sobre o que constitui a motivação como objeto de pesquisa, especialmente no campo da Educação e da docência. Inicialmente, fazemos a caracterização de construto e suas definições, para em seguida debater sobre as diferentes formas de enfocar teoricamente a motivação e analisá-la no contexto docente da Educação. Acostumados ao uso do termo motivação como um "coringa", retomar seu sentido científico, atribuindo-lhe balizas e limites constitutivos e operacionais é uma urgência na pesquisa sobre a temática.
\end{abstract}

Palavras-chave: Construto. Motivação. Educação superior.

\section{Teacher motivation: reflections on the construct}

Abstract: This reflexive essay aims to discuss teachers' motivation concept, description and research. It defends the need to understand motivation as a construct that although complex and multifaceted, demands conceptual and epistemological clarity besides the semantic and operational definition when applied in empirical research in the educational field. It proposes to offer aid to promote a fertile debate about what constitutes motivation as research object, especially in Education and teaching. The authors begin by characterizing the construct and its definitions. Then a debate about different ways to theoretically focus motivation and to analyze it in teaching and educational field is presented. Used to apply the term motivation as a "joker", it is urgent to recover its scientific meaning by attributing constitutive and operational signs and limits.

Key words: Construct. Motivation. Higher education. 


\section{Introdução}

Este ensaio reflexivo, cujo objetivo consiste em problematizar a conceituação, a descrição e a pesquisa da motivação docente, originou-se das evidências decorrentes da aplicação, pelas autoras, de uma metodologia de revisão sistemática em bases de dados. Com o propósito de reunir um corpus textual sobre a pesquisa empírica brasileira contemporânea sobre a motivação de docentes universitários, realizamos buscas em bases de dados online, utilizando diversos descritores combinados entre si de diferentes maneiras ${ }^{1}$, visando recuperar publicações dos últimos 14 anos (2000-2014), preferencialmente, em periódicos revisados por pares. Após a exclusão daqueles que não tinham a motivação como objeto central da pesquisa e/ou não estavam dirigidos aos professores universitários, encontramos quantidade bastante reduzida de publicações sobre a pesquisa com motivação docente e quase inexistente quando restritas ao âmbito da Educação Superior, sendo, neste último caso, selecionados apenas três artigos. Mesmo ampliando as buscas para outros portais ${ }^{2}$, incluindo também teses e modificando alguns descritores, os resultados não revelaram quantidade substancial de publicações.

Diante dessa evidência, instalou-se a inquietação e o desejo de reflexão, levando-nos a problematizar o paradoxo que constatamos ao observar o reduzido número de publicações disponíveis em bases de dados que efetivamente abordam a motivação no campo da pesquisa em Educação, especialmente quando dirigida ao professor, ao mesmo tempo em que esta é frequentemente citada nos estudos, seja na forma substantivada ou adjetivada, como um dos elementos essenciais à eficácia dos processos educativos e à valorização do professor. Corroborando essa afirmativa o próprio Plano Nacional de Educação destaca a relevância de termos profissionais da educação motivados para a qualidade da Educação (BRASIL, 2014).

Problematizamos assim: A que nos referimos quando citamos ou nomeamos "motivação" nas publicações? Há adequação conceitual na utilização do termo motivação nas

\footnotetext{
${ }^{1}$ Os descritores utilizados em português foram: motivação; educação superior; ensino superior; docentes; professores; universidade; professor universitário; processos motivacionais; processo motivacional; motivação escolar; motivação intrínseca; motivação extrínseca; motivação para ensinar. Foram consultados os portais Scientific Electronic Library Online - SciELO Brasil, Bibliografia Brasileira de Educação (BBE) e LILACS, rastreando-se título/assunto/palavras-chave pelos descritores, sendo recuperados 251 artigos: 222 na Scielo, 120 na LILACS e 17 na BBE. Destes, por meio dos resumos ou leitura dinâmica do texto completo, foram retidos apenas 100, a partir dos critérios de inclusão: apresentar evidências de pesquisa empírica sobre motivação docente, em Português do Brasil, realizadas com amostras brasileiras.

${ }^{2}$ Ampliamos as buscas para o portal CAPES, recuperando a partir dos descritores já citados, centenas de materiais, porém pelos critérios de inclusão/exclusão resultaram apenas publicações já recuperadas. Utilizando o descritor "professor universitário" ou "docente" em bancos de Teses, associado aos termos "motivação" e/ou "processos motivacionais" localizamos algumas dezenas de produções, porém os resumos revelaram que nenhuma incluiu a Educação Superior ou tratava da motivação como construto específico, sendo apenas referida como aspecto relacionado a outros fenômenos centrais da pesquisa, como subjetividade, bem-estar, satisfação com o trabalho, desenvolvimento de carreira, qualidade de vida, entre outros.
} 
pesquisas na área da Educação compatível com o status de construto? Quais as bases que sustentam a definição constitutiva e operacional do construto motivação para a pesquisa na área da Educação? A motivação docente é um campo de estudo aplicável e relevante à pesquisa científica?

Este ensaio reflexivo propõe-se, em última análise, a oferecer subsídios para a promoção do debate profícuo sobre o que constitui a motivação como objeto de pesquisa, especialmente no campo da Educação e da docência. Defende a necessidade de compreender e abordar a motivação como um construto que, embora complexo e multifacetado, demanda por clareza conceitual e epistemológica, além de definição semântica e operacional em sua aplicação nas pesquisas empíricas no âmbito da Educação. O caminho metodológico percorrido inicia pela retomada de autores clássicos, acrescidos das contribuições de autores atuais, voltadas à caracterização do que nomeamos por construto e suas definições no campo científico, para em seguida debater as diferentes formas de enfocar teoricamente a motivação, contextualizando-a no cenário docente da Educação Superior.

\section{O construto motivação: definições constitutiva e operacional}

Embora os termos "motivação" ou "motivado(a)" sejam com frequência utilizados na literatura científica, sua definição não é precisa, nem na área da Educação nem em muitas outras. Por vezes, a necessidade de observar a existência de diferenças e particularidades nos contextos onde a motivação é estudada tem sido utilizada, equivocadamente, como argumento para amenizar sua indefinição em termos de propriedades e características enquanto objeto de pesquisa.

Um fenômeno concreto, que exista independente da experiência subjetiva, pode ser reconhecido pela sua observação ou mensuração direta por meio de uma métrica estabelecida universalmente, tal como ocorre, por exemplo, com o peso, a altura, a distância, a velocidade ou a temperatura. De modo diverso, um fenômeno abstrato, como por exemplo, a inteligência, a aprendizagem, a depressão, o bem-estar, necessita primeiramente ser descrito por conceitos teóricos e representado por evidências reais para que seja explorado empiricamente. Conforme salienta Kaplan (1969, p. 65-66). "Os termos teóricos, conquanto devam ter seu significado analisado, e posto em conexão com a base empírica de todo o conhecimento, são indispensáveis para efetiva realização da investigação científica”. É nessa lógica que obtemos uma noção clara dos marcos e limites dos conceitos que definem fenômenos abstratos dentro do espaço semântico da teoria que os sustenta, estabelecendo-se assim como construtos (PASQUALI, 2010). 
Contudo, consideramos que tomar os termos "conceito" e "construto" como idênticos tem implicações para a pesquisa científica, sendo para esta mais relevante as distinções do que as similaridades entre ambos. Conceitos são representações mentais de objetos ou eventos, baseadas em características gerais e observáveis, expressos na forma de símbolos verbais; construtos são conceitos que envolvem níveis mais abstratos de representações mentais, construídos intencionalmente como edificações ideativas do plano mais simples ao mais complexo e, portanto, passíveis de serem decompostas (KERLINGER, 1973).

De acordo com Urbina (2004), um construto é definido como algo criado pela mente humana, que não pode ser diretamente observado, mas apenas inferido a partir de suas manifestações, sendo em sua forma pura um elemento latente, uma metáfora. Os construtos representam os significados ou interpretações que atribuímos aos eventos não concretos que existem no mundo real, significados esses que são internos e que só podem ser observados e nomeados por meio do comportamento ou reações determinadas. Do ponto de vista científico, uma abstração ou um conceito teórico é reconhecido como um construto apenas se for passível de ser identificado por seus atributos e características que o tornam único e reconhecível a partir de uma nomeação que lhe é atribuída, guardando o status de uma entidade específica, claramente distinguível de outras abstrações ou conceitos (FEIST; FEIST; ROBERTS, 2015).

Note-se, assim, que a distinção entre conceitos, construtos e termos teóricos é fluida e estabelecida em função do grau de sua abstração, dependendo também de sua aplicação em um contexto específico de investigação. A Tabela 1 sumariza a caracterização dessas denominações, de acordo com as ideias de Kaplan (1969).

Tabela 1 - Diferenciações entre conceitos, construto e termo teórico

\begin{tabular}{|c|c|c|c|c|}
\hline & \multicolumn{2}{|c|}{ CONCEITOS } & \multirow[t]{2}{*}{ CONSTRUTO } & \multirow{2}{*}{$\begin{array}{l}\text { TERMO } \\
\text { TEÓRICO }\end{array}$} \\
\hline & $\begin{array}{l}\text { Diretamente } \\
\text { observável }\end{array}$ & $\begin{array}{l}\text { Indiretamente } \\
\text { observável }\end{array}$ & & \\
\hline $\begin{array}{l}\text { Grau de } \\
\text { abstração }\end{array}$ & Grau 1 & Grau 2 & Grau 3 & Grau 4 \\
\hline Características & $\begin{array}{l}\text { Observáveis } \\
\text { /perceptíveis }\end{array}$ & $\begin{array}{l}\text { A partir do } \\
\text { observável são } \\
\text { inferidos os } \\
\text { detalhes }\end{array}$ & $\begin{array}{l}\text { Elaboração ideativa } \\
\text { intencional do significado } \\
\text { latente, com base nos } \\
\text { elementos observáveis }\end{array}$ & $\begin{array}{l}\text { Engloba conceito } \\
\text { e construto em } \\
\text { relação a uma } \\
\text { teoria }\end{array}$ \\
\hline Interpretação & Empírica & Empírica/descritiva & Empírica/descritiva & Teórica/ hipotética \\
\hline Expressão & Concreta & Abstrata inferencial & Abstrata simbólica & $\begin{array}{l}\text { Sistêmica, } \\
\text { abstrata teórica }\end{array}$ \\
\hline Exemplos & $\begin{array}{l}\text { Cores, fenótipo, } \\
\text { formas }\end{array}$ & $\begin{array}{l}\text { Genes, energia, } \\
\text { potência }\end{array}$ & $\begin{array}{l}\text { Inteligência, felicidade, } \\
\text { bem-estar }\end{array}$ & $\begin{array}{l}\text { Cultura, ética, } \\
\text { trauma }\end{array}$ \\
\hline
\end{tabular}

Fonte: Elaborada pelas autoras, baseadas em: KAPLAN, Abraham. A conduta na pesquisa. São Paulo: Herder, 1969. 
Assim para que um conceito indiretamente observável possa ser definido como um construto, passando do nível abstrato e teórico para o empírico e observacional, é necessário que lhe sejam atribuídas definições. A definição consiste em não deixar ambiguidades sobre o conceito teórico, tornando-o inconfundível. Porém, uma definição aplicável a um construto não é mero sinônimo de sua definição, mas tem a função de especificar significados e condições necessárias e suficientes para assegurar a aplicabilidade do termo definido (KAPLAN, 1969).

Um construto exige dois tipos de definições: a definição constitutiva (ou conceitual) e a definição operacional.Uma definição constitutiva é necessária quando o construto é definido por meio de outros conceitos já demarcados por uma teoria, que se juntam para dar-lhe corpo. Por exemplo, quando nos referimos à inteligência, que é um construto abstrato e latente, sabemos que esta representa um sistema complexo formado por diversos outros construtos, razoavelmente independentes, como o raciocínio (verbal, numérico, abstrato), a memória, a percepção espacial, atenção, etc. (PASQUALI, 2010).

Logo, se um construto envolve mais do que uma dimensão, ou seja, se tem dentro dele elementos representáveis e reconhecidos por si mesmos, ao pesquisá-lo devemos incluir todos, sob pena de obtermos apenas uma perspectiva parcial que, de fato, não o representa integralmente. Exemplificando: se desejamos conhecer um aspecto da inteligência que é a inteligência verbal devemos considerar que ela é formada por dois componentes, a compreensão verbal e a fluência verbal, e que cada um deles pode ser estudado separadamente, mas nesse caso, não estaríamos estudando a inteligência verbal em si, mas sim a compreensão verbal ou a fluência verbal (PASQUALI, 2010).

Nessa lógica, qual seria a definição constitutiva da motivação? De quais construtos ou atributos se utiliza para representar seu espaço semântico? Do que falamos quando denominamos "motivação"? A resposta a essas questões não é simples e deriva tanto da exploração minuciosa da teoria quanto da exaustiva pesquisa empírica.

Percebemos que após décadas de estudos sobre a motivação o conhecimento acumulado, tanto empírico quanto teórico, não tem sido suficientemente estruturado para nos proporcionar uma definição constitutiva sólida, que a represente com clareza. Todorov e Moreira (2005) compilaram, cronologicamente, um recorte das inúmeras conceituações semânticas encontradas para a motivação humana, em estudos da área da Psicologia, acabando por denunciar a heterogeneidade, por vezes conflitante, inserida nas publicações que exploram o conceito. E alertam que "Essa miscelânea conceitual evidencia não a quantidade de conhecimento que se tem sobre a motivação, mas a falta dele " (p.123). 
Reproduzindo a pesquisa de Todorov e Moreira (2005), porém, voltada para a área da Educação, entre as publicações brasileiras de 2005 a 2015, disponibilizadas na Scielo-Brasil, cruzando os descritores motivação e educação, os resultados corroboram a impressão desses autores sobre a falta de definição constitutiva clara à motivação, exemplificados no Quadro 1. Inclusive, muitos artigos localizados nessa busca continham a palavra motivação apenas no resumo ou nas palavras-chave, sem citá-la ou abordá-la efetivamente no corpo do artigo. Outros continham conceituações pouco definidas e autorais, constituindo-se, basicamente, de citações tangenciais, derivadas de estudos de outros autores. Alguns estudos, no entanto, apresentaram definições um pouco mais específicas para a motivação, como mostra o Quadro 1.

Quadro 1 - Algumas definições para motivação encontradas em publicações brasileiras na área da Educação (2005-2015)

\begin{tabular}{|c|l|}
\hline Autor (ano, página) & \multicolumn{1}{c|}{ Definições de motivação } \\
\hline $\begin{array}{c}\text { DAVIS; NUNES; NUNES } \\
(2005, \text { p. 210) }\end{array}$ & $\begin{array}{l}\text { "Motivação caracteriza-se por uma situação plena de energia, que leva a um esforço para atingir } \\
\text { um determinado objetivo, por intermédio de seleção atenta dos dados relevantes organização } \\
\text { de uma sequência integrada de estratégias de ação, persistindo na atividade até que as metas } \\
\text { iniciais sejam atingidas." }\end{array}$ \\
\hline $\begin{array}{c}\text { KNÜPPE } \\
(2006, \text { p. 278) }\end{array}$ & $\begin{array}{l}\text { "A motivação escolar é algo complexo, processual e contextual, mas alguma coisa se pode fazer } \\
\text { para que os alunos recuperem ou mantenham seu interesse em aprender." }\end{array}$ \\
\hline $\begin{array}{c}\text { PAULA; ENUMO } \\
(2007, \text { p. 21) }\end{array}$ & $\begin{array}{l}\text { "Este construto deve ser considerado como o componente indispensável para o sucesso escolar. } \\
\text { Sem ela, o estudante não terá iniciativas para aprender. Em outras palavras, é a motivação que } \\
\text { ativa as habilidades metacognitivas, além das funções cognitivas que envolvem aprendizagem." }\end{array}$ \\
\hline ECCHELI & $\begin{array}{l}\text { "O processo que se desenvolve no interior do indivíduo e o impulsiona a agir, mental ou } \\
\text { fisicamente, em função de algo. O indivíduo motivado encontra-se disposto a despender } \\
\text { esforços para alcançar seus objetivos." }\end{array}$ \\
\hline $\begin{array}{c}\text { JO08, p. 200) } \\
\text { CARRIERI (2013, p. 515) }\end{array}$ & $\begin{array}{l}\text { "A motivação pode ser considerada como um requisito, uma condição prévia da aprendizagem. } \\
\text { Sem motivação não há aprendizagem". "A motivação não é apenas algo natural, intrínseco ao } \\
\text { indivíduo, mas depende também de fatores externos." }\end{array}$ \\
\hline ZAMBON; ROSE & "Uma das limitações do uso de explicações sobre a presença ou ausência de motivação é o \\
(2012, p. 969) & $\begin{array}{l}\text { favorecimento de uma visão da motivação como um traço global e estável que o aluno tem ou } \\
\text { não tem." }\end{array}$ \\
\hline MARTINELLI & $\begin{array}{l}\text { "A motivação é vista como um componente energético do funcionamento individual e que atua } \\
\text { na direção, persistência e busca da finalidade, considerados aspectos da ativação e intenção." }\end{array}$ \\
\hline
\end{tabular}

Fonte: Elaborado pelas autoras

Entendemos que o risco implícito à falta de clareza constitutiva para a motivação é a não identificação dos atributos do construto. Na concepção psicométrica, atributos são aspectos ou propriedades que caracterizam o objeto de interesse da pesquisa e devem, de algum modo, apresentarem-se passíveis de serem operacionalmente identificados e examinados. Então, quais são os atributos inerentes à motivação?

Embora a literatura pouco aborde essa questão, há certa tradição na inclusão de três propriedades na definição e/ou abordagem da motivação: a forma de escolha da ação/atitude 
praticada, a persistência nessa ação e a intensidade do envolvimento/esforço dirigidos à mesma. Muito se especula acerca da influência dessas propriedades especialmente no processo intrapsíquico da motivação, considerando inclusive as perspectivas socioculturais que se voltam para elementos contextuais, supondo-se que a magnitude da motivação seja diretamente observável pela maior presença desses elementos, embora poucos estudos as explorem de fato.

Outro argumento relevante em favor de se estabelecer uma definição constitutiva clara para motivação, que permita tratá-la como um construto, é o risco de se tomar por idênticos a motivação e os comportamentos motivados ${ }^{3}$. Embora exista um sistema que se retroalimenta, temos que manter presente a noção de que a motivação desperta de necessidades humanas e não dos elementos que as satisfazem, entendendo-se, portanto, que o comportamento motivado é reativo à motivação que foi mobilizada pela necessidade. Sem entrar no mérito das nuances teóricas implícitas, a maioria dos estudiosos concorda que a motivação se estabelece em relação a algo (uma necessidade), levando a um circuito que demanda por satisfação ou eliminação. Porém, um elemento de satisfação da necessidade é de fato sua antítese, o que nem sempre tem sido bem compreendido. Por exemplo, o alimento é o fator de satisfação/eliminação da necessidade de fome, esta sim a verdadeira necessidade. Porém, como a fome demanda pelo alimento, em uma simplificação própria do senso comum, costumamos tratar o alimento como a necessidade ("preciso de comida") quando de fato ele é aquilo que satisfaz a necessidade.

Quando essa lógica do senso comum, inadvertidamente, é trazida para o campo científico, a confusão pode instalar-se, sendo ainda maior quando associada a necessidades abstratas. Por exemplo, a necessidade de ser acolhido gera demanda por reconhecimento, elogios, contato físico, etc., os quais são fatores de satisfação e não seus motivadores; da mesma maneira que o alimento (fator de satisfação de necessidade) está para a fome (fator motivador); a água (fator de satisfação de necessidade) para a sede (fator motivador). Porém, isso pode ter certa variabilidade (p. ex., em tempos de recessão ou guerras, a necessidade de estocar alimentos pode se converter em uma necessidade ou fator motivacional), de tal modo que deve haver cautela no estabelecimento de fatores genéricos de motivação e de satisfação.

É fundamental a clareza dessa dinâmica funcional para a definição constitutiva da motivação. Pode-se prover fatores de satisfação (ou contra-satisfação), mas isso não equivale

\footnotetext{
3 Para os neurocientistas, comportamentos motivados são aqueles fundamentais para a sobrevivência do indivíduo ou de sua espécie por atenderem necessidades vitais, como o comportamento alimentar, reprodutor ou defensivo.
} 
a gerar uma necessidade. Necessidades de fome, sede, estima, autonomia, cuidado e muitas outras já existem, em estado latente, como parte da condição humana e são fatores motivacionais por si mesmo. A confusão dessa compreensão pode estar associada, em parte, à noção de condicionamento sustentada pelos teóricos comportamentalistas, o qual produziria respostas esperadas frente à recompensa/punição, que não necessariamente se associam à motivação.

Por outro lado, além da motivação distinguir-se do comportamento motivado também se diferencia do estilo motivacional. Este abarca sentimentos e comportamentos demonstrados nas interações com outras pessoas, sendo muitas vezes alvo da pesquisa relacionada à motivação no campo educacional (ver, por exemplo, MACHADO et al., 2012; BZUNECK; GUIMARÃES, 2007; REEVE, 2009). O estilo motivacional "é considerado uma característica decorrente da personalidade, do aprendizado e de influências do contexto social" (MACHADO et al., 2012, p. 191), podendo impactar sobre diversos aspectos no cenário educacional, mas não se constitui na própria motivação.

A definição operacional de um construto, por sua vez, parte do campo teórico no qual o pesquisador se fundamenta, mas se desloca para o campo concreto, devendo ser visível por meio de suas formas de expressão e manifestação (PASQUALI, 2010). Será de fato operacional se define ações/comportamentos manifestos, possíveis de realização pelo sujeito. Se, por exemplo, definimos motivação como "a capacidade de persistir em um objetivo" (definição constitutiva) a definição operacional da persistência deve ser representada por algumas ações do sujeito nessa direção, as quais possam ser mensuradas ou narradas, tais como, "não chegar atrasado", "cumprir prazos", "buscar soluções alternativas para resolver um problema".

Contudo, a definição operacional além de ser representável, deve ser abrangente para cobrir o máximo possível da definição do construto, o que implica muitas vezes em obter a evidência de diferentes formas (p.ex., por diferentes itens de uma escala que abordem a questão) ou fontes (p.ex., autorrelatos, relatos de outros, observações). Em outras palavras, as definições operacionais demandam que todo o conhecimento sobre o construto, derivado tanto da literatura, da experiência, da pesquisa empírica, do saber de especialistas ou de qualquer outra fonte confiável deve ser explorado e, principalmente, armazenado para ser acessado ao longo do tempo, e é sobre esse conhecimento cumulativo que um construto se define operacionalmente. 
Alguns autores, como Selltiz, Wrightsman e Cook (1972), denominam a definição operacional como "definição de trabalho":

\begin{abstract}
Definições de trabalho são adequadas se os instrumentos ou processos neles baseados obtêm dados que constituam indicadores satisfatórios dos conceitos que pretendem representar. Saber se esse resultado foi conseguido é, frequentemente, uma questão de opinião. Um pesquisador pode pensar que seus dados apresentam indicadores razoavelmente bons de seus conceitos; um crítico do estudo pode pensar que isso não ocorre. Frequentemente acontece de o pesquisador estar ciente de que seus dados constituem apenas um reflexo muito limitado do conceito que tem em mente, mas, sobretudo nos estágios iniciais da pesquisa de um problema, pode não ser capaz de criar um conceito mais satisfatório. De qualquer forma, embora, geralmente o pesquisador relate seus resultados através de conceitos abstratos, a fim de ligá-los mais facilmente a outras pesquisas e à teoria, ele e seus leitores devem lembrar que, na realidade, encontrou uma relação entre dois conjuntos $^{5}$ de dados que, segundo pretende, representam também seus conceitos (p. 51-52).
\end{abstract}

Note-se, assim, que uma definição constitutiva só obtém significado para a pesquisa científica quando se revela como será utilizada em uma aplicação ou operação específica, em um contexto determinado. Isso significa que as definições operacionais de um mesmo construto podem variar de acordo com contextos particulares, sendo, portanto, mais adequado focar na utilidade dessas definições do que na sua correção ou incorreção simplesmente.

Por outro lado, é fundamental ao pesquisador a consciência de que definições operacionais muito parcimoniosas podem obscurecer a definição constitutiva de um construto, focando-se em aspectos muito óbvios ou apenas em certos aspectos em detrimento da perspectiva global, o que por usa vez limita também a apreensão e compreensão de dada realidade. Portanto, explorar a fidedignidade e validade das definições operacionais é imprescindível para a mensuração adequada de um construto, o que parece mais bem esclarecido no que tange à pesquisa quantitativa (PASQUALI, 2010). Porém, ainda que seja uma pesquisa qualitativa, de modo equivalente, o pesquisador terá que posicionar-se à priori sobre a base constitutiva e epistêmica do construto que pretende estudar, sem o que a obtenção da informação/dados a serem analisados ficará comprometida e a interpretação se tornará pífia, de tal modo que qualquer resultado será considerado pertinente. E, lamentavelmente, sempre há o risco de tais resultados serem inadvertidamente tomados como confiáveis.

Sabemos que a dimensão semântica é sempre uma construção cultural, a partir da expressão simbólica de um fenômeno. Por isso, pode ser tão vulnerável às contingências quanto às definições operacionais. Do ponto de vista da pesquisa científica, a consistência

\footnotetext{
${ }^{4}$ Foi realizada a adequação ortográfica do texto pelas autoras, seguindo as normas atuais.

${ }^{5}$ Itálico reproduzido como no texto original.
} 
semântica e operacional é extremamente relevante, consolidando a indispensabilidade da validação transcultural de definições, técnicas e instrumentos relativos a um construto.

\section{Antigas incertezas: motivação é traço, processo ou estado?}

A motivação pode ser concebida como uma qualidade específica de alguns indivíduos, resultado de traços de personalidade, ou como uma estratégia de enfrentamento das situações, ou como um estado transitório? Se entendida como um traço, na abordagem clássica, representaria uma disposição para se comportar de uma forma particular em situações distintas, e na concepção de alguns seria, então, resultante de aspectos mais inatos do que passível de ser adquirida.

Allport (1955), um dos pioneiros na teorização da motivação, opondo-se a ideia clássica de que as "disposições motivacionais" fossem inatas ou inconscientes, defendia que um traço de personalidade não é necessariamente inato, podendo desenvolver-se em função das experiências vividas e da cultura. Por exemplo, manter os objetos organizados é um hábito adquirido, mas a ordem pode ser um traço de personalidade que foi desenvolvido por meio da educação.

Assim, Allport $(1955,1961)$ atribuía as diferenças marcantes da motivação à presença de esforços do proprium $^{6}$ que visam manter a tensão e o desequilíbrio e motivos periféricos voltados a reduzir uma necessidade. Então, a pessoa adulta e madura estaria motivada não somente a reduzir a tensão e retornar ao estado de equilíbrio, mas a agir deliberadamente sobre o ambiente na busca de mudança e crescimento. Tais ideias levaram-no a conceber o comportamento proativo como mais relevante que o reativo, pois a ação proativa permitiria adquirir novos sistemas de motivação, independentes dos eventos passados, embora também reconhecesse que o sujeito pudesse ter motivações reativas. Denominava de traços motivacionais aquelas disposições pessoais que iniciam as ações e que poderiam ter forças variáveis (cardinais, centrais ou secundárias).

Allport (1961) contribuiu para uma definição da motivação, mas também promoveu ambiguidades, que se refletem até os dias atuais: algumas motivações podem ser conscientes e outras inconscientes; umas transitórias, outras permanentes; servem ora para reduzir a tensão ora para mantê-la. Embora pretendesse uma teoria abrangente e unificadora, constatou-se que suas ideias eram aplicáveis a certos tipos de motivação, isto é, a de adultos psicologicamente

${ }^{6} \mathrm{O}$ propium representa o centro da personalidade, inclui aspectos considerados vitais para o senso de identidade pessoal e para o autocrescimento. 
saudáveis. Serviram de base, contudo, para que novas possibilidades teóricas fossem concebidas. Assim, na atualidade, estudos específicos abordam a motivação mais como um processo (do que como um traço individual), que envolve a personalidade e que se desenvolve dinamicamente na interação do sujeito com suas necessidades, seu contexto e suas experiências, assumindo sempre um caráter relativo.

Porém, a aplicabilidade demostra que essas diferenciações conceituais da motivação não foram ainda suficientemente processadas, nem mesmo no meio acadêmico. Enfatizamos que o viés "motivação-traço/característica pessoal" encontrado em muitas pesquisas na Educação demanda por concepções bem estabelecidas sobre a Teoria dos Traços de Personalidade e que a perspectiva processual demanda abandonar a descrição dicotômica (motivado/desmotivado), ainda tão frequentemente vista nas publicações. Além disso, a transposição do entendimento das teorias da motivação de uma área de conhecimento para outra não pode ser linear. No campo da Psicologia os estudos da motivação derivaram inicialmente da exploração do desenvolvimento psicológico, com vertentes tanto humanistas (Maslow e Rogers), quanto comportamentalistas (Pavlov, Skinner e seus seguidores); do desenvolvimento da personalidade por meio das contribuições da psicologia do indivíduo (Allport e McCrae e Costa) e da psicologia evolucionista (Eysenck e Buss), a maioria das quais explorou conjuntamente a teoria psicométrica. Já no campo da Educação, as teorias sociocognitivas têm sido utilizadas com maior frequência, com destaque para a Social Cognitiva e da Aprendizagem Social, além de outras mais híbridas como a Teoria da Autodeterminação e a das Metas de Realização.

Concordamos com Feist, Feist e Roberts (2015) quando afirmam que uma teoria útil à ciência não deve se apoiar em valores e predileções pessoais. Ao contrário, deve atender a seis pressupostos objetivos: gerar pesquisa; ser refutável; organizar dados; orientar a ação; ser internamente coerente; ser parcimoniosa. Esse último aspecto, a parcimônia, talvez o mais difícil de ser encontrado nas teorias da motivação, implica que a teoria seja abrangente o bastante para não ser reducionista, porém simples o suficiente para não ficar "atolada sob o peso de conceitos complicados e linguagem esotérica” (p. 8).

Por outro lado, considerando que a motivação pressupõe sempre uma direção, é lógico supor que se associa a determinado intervalo de tempo. Esse intervalo pode ser mais temporário (situacional) ou mais sustentável, dependendo de todos os elementos idiossincráticos envolvidos e dos que se mantiveram constantes. A motivação, vista desse ângulo interativo e dinâmico, leva-nos a inferir que "estar" motivado em uma situação não garante nem possibilita prever se o sujeito se mostrará motivado no futuro, especialmente, sob 
influência de contingências diferentes. Nesse sentido, portanto, é sempre um estado transitório e fluido, dirigido a um objetivo que pode ser imediato ou futuro, direta ou indiretamente alcançável, e neste último caso, o sujeito terá que mover-se dos objetivos mais próximos para os mais distantes.

No entanto, se concebermos a motivação como um estado mental, muitas questões podem se apresentar ao debate epistêmico, considerando a suposição de que estados mentais podem ser conhecidos por introspecção, em contraponto, por exemplo, ao behaviorismo filosófico o qual nega ou ignora o aspecto subjetivo dos estados mentais. Para os teóricos dessa corrente toda sentença sobre estado mental pode ser parafraseada, sem perda de significado, numa longa e complexa sentença sobre qual comportamento observável iria resultar se a pessoa estivesse nesta ou naquela ou em outra circunstância (RYLE, 2000). Embora essa discussão nos leve para longe dos propósitos desse estudo, é necessário destacar que a definição operacional da motivação é indissociável da sua definição constitutiva operacional e distinta dos pressupostos do comportamentalismo filosófico.

\section{A motivação frente à docência}

O planejamento das metas do Plano Nacional de Educação/PNE/2014-2024 aponta de forma explícita a relevância do processo motivacional para a qualidade da Educação e para a formação de novos profissionais, por meio da Educação Superior, elencando diversas variáveis que podem se relacionar a esse processo:

\footnotetext{
Um quadro de profissionais da educação motivados e comprometidos com os estudantes de uma escola é indispensável para o sucesso de uma política educacional que busque a qualidade referenciada na Constituição Brasileira. Planos de carreira, salários atrativos, condições de trabalho adequadas, processos de formação inicial e continuada e formas criteriosas de seleção são requisitos para a definição de uma equipe de profissionais com o perfil necessário à melhoria da qualidade da educação básica pública (BRASIL, 2014, p.12-13).
}

Diante disso, discutir a motivação em relação à docência torna-se um ponto ainda mais urgente, visto que essa motivação não vem ocupando significativamente o interesse acadêmico. As buscas já referidas que realizamos em bases de dados para obter um corpus textual sobre a motivação docente, evidenciou a existência de literatura direcionada à motivação para a aprendizagem em quantidade mais representativa do que aquela relacionada à motivação docente. Segundo Boruchovitch (2010), a "motivação para a aprendizagem" vem sendo definida como "a iniciação e manutenção de comportamento com o objetivo de atingir uma determinada meta" (p.119). Concebemos que isso não parece verdadeiro apenas para o estudo da motivação para a aprendizagem, senão que se apresenta em todo campo do estudo 
da motivação. A autora refere-se a essa motivação como "acadêmica", destacando a necessidade de abordá-la em uma perspectiva multidimensional, com utilização de pressupostos teóricos distintos e complementares, devido à inexistência de uma teorização específica.

Entendemos que a presença de um foco sobre o qual dirigir questionamentos e metodologias simplifica e torna viável a busca de respostas e a delimitação do campo de pesquisa. Porém, é exatamente no estabelecimento de um foco, no caso a aprendizagem, que podemos observar uma das distinções que acompanham a pesquisa da motivação com estudantes e a da motivação docente, esta última menos específica e difusa.

Para pensar a pesquisa sobre motivação docente, faz-se necessário começar por definir o que denominamos "docência", campo marcado por desafios e sentidos contemporâneos que precisam conviver com perspectivas históricas. Por longo tempo, o sentido difundido nos países Latino-Americanos aproximou a docência de um "apostolado" e "um serviço social" (CAMPOS, 2007, p.16), envoltos na alcunha "vocação". Como sintetiza Campos, a definição de docência requer uma perspectiva integral:

\begin{abstract}
O que significa a profissão docente hoje? Ter profissionalismo e compromisso social, o que implica: (1) pensar e pensar-se como docentes não só ocupados com as tarefas didáticas, mas numa dimensão maior que inclui a gestão escolar e as políticas estratégicas educacionais; (2) ser protagonista das mudanças e capaz de participar e intervir nas decisões da escola e em espaços técnico-políticos mais amplos; (3) desenvolver capacidades e competências para trabalhar em cenários diversos, interculturais e em permanente mudança; (4) atuar com gerações que têm estilos e códigos de comunicação e aprendizagens diversos, com novas exigências e desafios à competência dos docentes (CAMPOS, 2007, p.17).
\end{abstract}

Diante dessa concepção, estabelecer um foco para a pesquisa sobre a motivação docente têm implicações, pois abrange distintas e complexas facetas. Diferentemente da pesquisa direcionada aos estudantes, que tem sido sumarizada em "motivação para a aprendizagem", não parece adequado sumarizar aquela direcionada aos docentes em “motivação para ensinar", sob pena de excluirmos todas as demais atividades e contingências que se inserem na concepção de docência, entre elas, a pesquisa e a gestão e própria perspectiva de carreira. Talvez essa dificuldade, ainda muito pouco debatida, represente um dos obstáculos ao avanço da pesquisa sobre a motivação docente, evidenciada na escassez de publicações sobre a temática. Além disso, abordar a motivação docente nessa perspectiva da “motivação para ensinar", como mostra um estudo de Joaquim, Vilas Boas e Carrieri (2012),

\footnotetext{
7 Percebemos que boa parte dos estudos faz uso da expressão "motivação acadêmica" como equivalente de motivação para a aprendizagem, o que em nossa opinião demanda por reflexão que está além dos propósitos deste artigo, uma vez que a aprendizagem é um dos elementos do contexto acadêmico, e este envolve muitos outros elementos, tais como, criatividade, desempenho, pensamento crítico, estratégias adaptativas, evasão, desenvolvimento social, expectativas futuras, ente outros.
} 
pode resultar na ênfase em sua estreita, porém ambígua, relação com o desempenho em sala de aula e, por extensão, acabar por colocá-la como condição prévia para a aprendizagem discente, tendo o aluno com referência maior para a sua avaliação.

Tão pouco nos parece suficiente abordar os processos motivacionais docentes desde a perspectiva organizacional, como tipicamente se faz no campo da administração e gestão de pessoas. Em geral, no âmbito organizacional, a motivação se atrela à avaliação de desempenho e plano de carreira. Corroborando essa perspectiva, Campos (2007, p. 17) afirma que "Hoje falar de docente, geralmente, é falar de capacitação, salários e avaliação de desempenho", alertando que isso não reflete positivamente nem em remuneração nem em qualidade de vida para os docentes. Entendemos que a motivação vista nessa perspectiva é insuficiente para atender a concepção integral da docência, pondo sua pesquisa muito mais ao serviço da lógica capitalista do que dos propósitos educacionais e desenvolvimentais.

O coordenador de estudos sobre sistemas de carreira e de avaliação docente na América e Europa, referindo-se à avaliação de desempenho docente na América Latina, aponta:

\begin{abstract}
Na maioria dos países que conta com um sistema de avaliação externa de desempenho docente, dois são os propósitos da avaliação: (i) melhorar e assegurar qualidade de ensino (função formativa); e (ii) utilizar as informações colhidas para classificar ou selecionar docentes e decidir sobre sua vida profissional, com repercussão em seu salário, promoção, ou até definição de seu futuro como docente (função somativa) (TORRECILLA, 2007, p. 23).
\end{abstract}

Nessa lógica, nossa experiência com a pesquisa sobre motivação docente tem revelado que a associação entre motivação e avaliação de desempenho, explícita ou implicitamente reconhecida, repercute sobre o interesse e a participação dos professores nos estudos. Embora, em tese, os docentes valorizem a necessidade de se pensar a motivação docente, a disponibilidade efetiva para tornarem-se sujeitos/participantes das pesquisas sobre o tema é vista com reserva e, não raras vezes, se apresenta como um esquivamento ou até recusa formal em colaborar. Talvez incida o temor de que as informações sejam uma forma de monitoramento de seu desempenho, muito embora os esclarecimentos sobre os verdadeiros objetivos das pesquisas sejam enfatizados.

Diante disso, parece-nos inevitável questionar como a motivação dos professores tem sido tratada pelas instituições de ensino. Poucos são os estudos que trazem evidências que respondam adequadamente a esse questionamento. Um estudo realizado por Konzen e Adams (2016) exemplifica como, geralmente, a avaliação da motivação docente tende a ser extraída de informações que integram as avaliações institucionais, sumarizando três formas típicas de abordá-la institucionalmente: pela perspectiva do aluno, pela perspectiva do próprio professor 
e pelo cruzamento das duas primeiras como o desempenho. No entanto, esse modelo atrelado à avaliação institucional, e mais especificamente à avaliação de disciplinas, pode não considerar adequadamente a natureza multifatorial e as definições constitutivas e operacionais do construto motivação, havendo o risco de tomar comportamentos motivados como idênticos à motivação, como já apontado, fazendo com que as conclusões que dele emerjam sejam simplistas, parciais e incompletas, induzindo a enfoques pouco fidedignos quanto à compreensão dos verdadeiros processos motivacionais.

A utilização de recursos como instrumentos de medida específicos, desenvolvidos a partir de perspectivas teóricas e epistemológicas bem especificadas, fundamentados na ciência psicométrica contemporânea (PASQUALI, 2010; URBINA, 2004), que posicionem o sujeito como ponto central da avaliação e o construto como objeto da investigação, pode ser um caminho estratégico viável para a avaliação da motivação docente no contexto da Educação Superior. Entendemos que além de contornar os vieses e extrapolações inerentes ao seu atrelamento aos programas de avaliação institucional, investigar a motivação a partir das necessidades intrínsecas apoiando-se em ferramentas adequadas tende a fornecer informações muito mais relevantes ao desenvolvimento de políticas e programas que de fato promovam engajamento, vitalidade e bem-estar docente.

Consta-se, portanto, que diante da escassez de estudos dirigidos à motivação como objeto específico e central da pesquisa muitas inferências comumente feitas acerca da motivação docente demandam por aprofundamento, sendo elas, possivelmente, resultado de conclusões transversais ou até especulativas. É exatamente esse rigor em explorar possíveis achados sobre a motivação quem sustenta os avanços no desenvolvimento constitutivo e operacional de um construto latente. Conhecer o que os docentes percebem em relação a si mesmos, às suas necessidades e ao seu contexto parece ser o caminho mais confiável para produzir sentido e nexo ao que chamamos de motivação docente, o que demanda por pesquisas direcionadas a todos os níveis de ensino, particularizando e mapeando as diferenças inseridas em cada realidade. Exemplo disso é um estudo qualitativo realizado com docentes da Educação Superior que aponta dez aspectos por eles percebidos como as principais razões para a permanência na carreira docente, citados por ordem de relevância: a relação com alunos; a formação continuada; gosto/prazer/satisfação pela docência; envolvimento com a pesquisa científica; o salário; a contribuição social da atuação; o ambiente acadêmico; a autonomia; segurança/estabilidade/prestigio; os desafios/compartilhamento do conhecimento (SANTOS; DAVOGLIO; SPAGNOLO, 2013). Resta saber a quais necessidades motivacionais atendem. 
Acostumados ao uso da motivação como um "coringa", retomar seu sentido científico, atribuindo-lhe balizas e limites constitutivos e operacionais é uma urgência na pesquisa sobre a temática. O que é observado nem sempre corresponde ao fenômeno nomeado quando falamos de construtos abstratos e complexos. Assim, por exemplo, há queixas dos professores em todos os níveis escolares sobre desmotivação de alunos.

O que tais professores querem dizer, porém, é o que observam: que seus alunos (ou alguns deles) não estão revelando aquela dedicação desejável aos estudos e, ao contrário, apresentam comportamento de indisciplina. Em outros casos os professores estão fazendo atribuições de causalidade ao fracasso dos alunos. Se não estão rendendo como o esperado então estão desmotivados (BZUNECK, 2009, p. 15).

Acreditamos que compete substancialmente à acadêmica restituir aos processos motivacionais apenas a sua cota de responsabilidade como protagonista nos problemas discentes e docentes observados em sala de aula. Há inúmeros outros fenômenos (que não a motivação) que afetam desempenho, aprendizagem, rendimento, comprometimento, participação, concentração, criatividade e comportamento no meio educacional e que devem ser examinados em suas especificidades. Além disso, no contraponto, encontra-se a responsabilização excessiva do docente na motivação do aluno, como intuito de que fenômenos como os recém citados, bem como a evasão e a reprovação, não se manifestem fora do ideal na sala de aula. É necessária cautela na propagação da crença de que a mudança de níveis motivacionais pode se dar sem investimentos e alterações estruturais em fenômenos sociais, psicossociais, cognitivos, políticos, demográficos entre outros que impactam na Educação.

\section{À guisa de considerações conclusivas}

Possivelmente diante da dificuldade de apreender um significado semântico e operacional para a motivação, por sua própria complexidade, facilmente toma-se suas consequências ou fenômenos que a acompanham como sinônimos da mesma, o que tem sido observado também em relação a outros construtos complexos como a qualidade de vida (DAVOGLIO; LETTNIN; BALDISSERA, 2015) ou a resiliência (REPPOLD et al., 2012). A partir do conhecimento empírico acumulado, sabemos que a motivação se correlaciona e se imbrica com aspectos e construtos cognitivos (p.ex., atenção, memória, concentração), afetivos (p.ex., satisfação, interesse, disposição, bem-estar, qualidade de vida), comportamentais (p.ex., desempenho, persistência, pro-atividade). Mas a base constitutiva da motivação não pode ser explicada de forma direta ou linear por tais elementos, sob pena de afundarmos no perigoso terreno das especulações tautológicas. 
Esse árduo trabalho de construção constitutiva e epistêmica de um construto antecede e acompanha a pesquisa empírica, numa via de mão dupla, e nem sempre é fácil resistir a sua aplicação antes de se estabelecer sólida concepção teórica que norteie as conclusões. Como aponta Bergamini (2006), ao conceituar a motivação em termos organizacionais, a observação simples e imediata do comportamento motivado não responde à compreensão das bases etiológicas e epistemológicas da motivação, sem as quais não podemos precisar as balizas e limites que possui.

Constatamos diante das reflexões já apresentadas, a necessidade de tecermos definições constitutivas, sobre as quais se construam definições operacionais para a motivação. Em nossa concepção, a motivação assume a forma de uma energia inerente ao sujeito, a qual exige ser nutrida e potencializada continuamente. Consideramos que as antigas discussões sobre sua natureza dicotômica, intrínseca ou extrínseca, estão superadas, pois pode atingir graus e formas variáveis de expressividade (como sugere, por exemplo, a SelfDetermination Theory) sendo precisamente a conjugação dessa variabilidade que sustenta a fluidez e o dinamismo do processo motivacional. Acreditamos que em sua forma pura, a motivação manifesta-se como uma potencialidade humana, sujeita às contingências situacionais e contextuais, além da influência dos recursos pessoais, afetivos e cognitivos disponíveis. Em sua forma aparente consiste em um foco voluntário, intencional e persistente em uma direção específica. Voluntário nesse caso significa deliberado, sem ser, necessariamente, sinônimo de autodeterminado, pois, a pessoa pode estar sob influências externas, coercitivas ou não, ainda que mantendo o livre arbítrio. É intencional por não ser aleatório, impulsivo, fruto do acaso ou do desconhecimento. É persistente referindo-se à permanência suficiente desse foco para ser identificado através do tempo, não se resumindo a uma intenção fugaz ou imediata.

Concordar com essa definição consiste também em aceitar que mesmo diante de fatores hipoteticamente promotores de motivação, a pessoa poderá não se demonstrar motivada. Não há uma combinação única de elementos e forças, ambientais e internas, que leve necessariamente a sua efetivação.

Paradoxalmente, isso não implica a pressuposição automática de que se a pessoa não estando motivada, logo estará desmotivada. Isso porque a motivação pode apresentar momentos de passividade e de silenciamento/afastamento necessários para o processamento e a internalização dos estímulos e demandas, tanto internos quanto ambientais, antes de uma reação, ou até mesmo para o fortalecimento de uma decisão/ação já estabelecida. Momentos esses, não raras vezes, nomeados com precipitação, associando-os a um "afrouxamento" 
motivacional, especialmente, pelos observadores externos. Levantamos a hipótese de haver diferença entre "amotivação"8 e desmotivação. A partir disso, a desmotivação talvez devesse ser explorada como um construto correlato à motivação, pois, parece sujeita a uma conjugação de elementos que não apenas ou necessariamente resumam-se aqueles implicados na motivação.

O uso adjetivado da motivação, visível na expressão "professor/aluno motivado" ou "professor/aluno desmotivado", nos parece mais uma inferência especulativa do que uma constatação baseada na exploração da motivação em sua forma substantivada, como um construto. Entendemos ser prioridade restituir o sentido teórico e epistemológico ao termo motivação na área da Educação, quase sempre utilizado como sinônimo ou complemento de algum outro fenômeno (por exemplo, bem-estar, rendimento ou desempenho), descaracterizando-o como construto no campo da pesquisa.

Nossa constatação de que os estudos sobre a motivação docente no Brasil ainda são incipientes, cuja publicação é escassa, é uma informação valiosa. Se por um lado aponta um campo de pesquisa que demanda investimentos, por outro anuncia a possibilidade de edificarmos esse campo sobre alicerces constitutivos e operacionais sólidos e metodologicamente confiáveis, que deem sentido e sustentação para o desenvolvimento de avanços que possam subsidiar políticas públicas voltadas à profissão e formação docente, em consonância com as metas do PNE/2014-2024.

Contudo, acreditamos que existem muitas publicações sobre a motivação que não foram acessadas nas revisões que serviram de mote para este estudo, especialmente por não estarem suficientemente acessíveis à consulta. É oportuno apontar a necessidade do estabelecimento e utilização de descritores indexados em produções científicas da área da Educação, que unifiquem e direcionem as buscas em bases de dados, a exemplo do que ocorre no cenário internacional. Embora no Brasil se conheçam alguns canais com descritores destinados à indexação e à recuperação de informações, como, por exemplo, o Thesaurus Brasileiro da Educação/BRASE9 (http://portal.inep.gov.br/pesquisa-thesaurus), nele não consta o descritor motivação, diferentemente do que se observa quando se introduz o termo "motivation" no Thesaurus da Education Resources Information Center/ERIC (http://eric.ed.gov/thesaurus).

\footnotetext{
${ }^{8}$ A exemplo do que ocorre na saúde, onde estar "assintomático" não representa estar livre da doença.

${ }^{9}$ É um vocabulário controlado que reúne termos e conceitos, extraídos de documentos analisados no Centro de Informação e Biblioteca em Educação (CIBEC), relacionados entre si a partir de uma estrutura conceitual da área.
} 


\section{Referências}

ALLPORT, Gordon Willard. Becoming: Basic consideration for a psychology of personality. New Haven, CT: Yale University Press, 1955.

ALLPORT, Gordon Willard. Pattern and growth in personality. New York: Holt, Rinehart and Winston, 1961.

BERGAMINI, Cecília. W. Motivação nas organizações. São Paulo: Atlas, 2006.

BRASIL. Ministério da Educação. Secretaria de Articulação com os Sistemas de Ensino Planejando a próxima década conhecendo as 20 metas do Plano Nacional de Educação.

2014. Disponível em:〈http://pne.mec.gov.br/images/pdf/pne_conhecendo_20_metas.pdf >. Acesso em: 19 mar. 2015.

BZUNECK, José Aloyseo; GUIMARÃES, Sueli ÉdiRufini. Estilos de professores na promoção da motivação intrínseca: reformulação e validação de instrumento. Psicologia:

Teoria e Pesquisa, Brasília, v. 23, n. 4, p. 415-422, out./dez., 2007.

BZUNECK, José Aloyseo. A motivação do aluno: Aspectos introdutórios. In:

BORUCHOVITCH, Evely; BZUNECK, José Aloyseo. A motivação do aluno: contribuições da psicologia contemporânea. Petrópolis: Vozes, 2009. p. 9-36.

BORUCHOVITCH, Evely. A motivação no contexto escolar: implicações para a formação de professores In: SANTOS, BettinaSteren dos; CARREÑO, Angel Boza (Orgs). A motivação em diferentes cenários. Porto Alegre: EdiPUCRS, 2010. p.119-128.

CAMPOS, MagalyRobalino. Profissão Docente: Novas perspectivas e desafios no contexto do século XXI. In: BALZANO, Sônia (Org.). O desafio da profissionalização docente no Brasil e na América Latina. Brasília: CONSED, UNESCO, 2007. p. 15-21.

DAVIS, Claudia; NUNES, Marina M. R.; NUNES, Cesar A. A. Metacognição e sucesso escolar: articulando teoria e prática. Cadernos de Pesquisa, São Paulo, v. 35, n. 125, p. 205 230, maio/ago. 2005.

DAVOGLIO, Tárcia Rita; LETTNIN, Carla da Conceição; BALDISSERA, Cristina Generalli. Avaliação da qualidade de vida docente: uma revisão sistemática. Pro-Posições, Campinas, v. 26, n. 3, set./dez. 2015.

ECCHELI, Simone D. A motivação como prevenção da indisciplina. Educar, Curitiba,n. 32, p. 199-2013, 2008.

FEIST, Jess; FEIST, Gregory J.; ROBERTS, Tomi-Ann. Teorias da personalidade. 8. ed. Porto Alegre: AMGH, 2015.

JOAQUIM, Nathália de Fátima; VILAS BOAS, Ana Alice; CARRIERI, Alexandre de Pádua. Estágio docente: formação profissional, preparação para o ensino ou docência em caráter precário? Educ. Pesqui., São Paulo, v. 39, n. 2, p. 351-365, abr./jun. 2013.

JOAQUIM, Nathália de Fátima; VILAS BOAS, Ana Alice; CARRIERI, Alexandre de Pádua. Entre o discurso praticado e a realidade percebida no processo de formação docente.

Avaliação, Campinas; Sorocaba, SP, v. 17, n. 2, p. 503-528, jul. 2012.

KAPLAN, Abraham. A conduta na pesquisa. São Paulo: Herder, 1969.

KERLINGER, Fred N. Foundations of behavioral research. 2.ed. New York: Holt, Reinehart \& Winston, 1973. 
KNÜPPE, Luciane. Motivação e desmotivação: desafio para as professoras do ensino fundamental. Educar, Curitiba, n. 27, p. 277-290, 2006.

KONZEN, Léo Zeno; ADAMS, Elias. Autoavaliação institucional: um estudo sobre a análise de dados da autoavaliação em perspectiva diacrônica. Avaliação, Campinas; Sorocaba, SP, v. 21, n. 3, p. 783-798, nov. 2016.

MACHADO, Amélia Carolina Terra Alves; RUFINI, Sueli Édi; MACIEL, Aline G.; BZUNECK, José Aloyseo. Estilos motivacionais de professores: preferência por controle ou por autonomia. Psicologia: Ciência e Profissão, Brasília, v. 32. n. 1, p. 188-201, 2012.

MARTINELLI, Selma de Cássia. Um estudo sobre desempenho escolar e motivação de crianças. Educar em Revista, Curitiba, n. 53, p. 201-216, jul./set. 2014.

PASQUALI, Luis. Instrumentação psicológica: Fundamentos e prática. Porto Alegre: Artmed, 2010.

PAULA, Kely Maria Pereira de; ENUMO, Sônia Regina Fiorim. Avaliação assistida e comunicação alternativa: procedimentos para a educação inclusiva. Rev. Bras. Ed. Esp., Marília, v. 13, n. 1, jan./abr. 2007.

REEVE, Johnmarshall. Why teachers adopt a controlling motivating style toward students and how they can become more autonomy supportive. Educational Psychologist, Washington, v. 44, n. 3, p.159-175, 2009.

REPPOLD, Caroline Tozz; MAYER, Jeferson Charles; ALMEIDA, Leandro Silva, HUTZ, Claudio. Avaliação da resiliência: controvérsia em torno do uso das escalas. Psicologia:

Reflexão e Crítica[online], Porto Alegre, v.25, n.2, p. 248-255, 2012. Disponível em: $<$ http://www.scielo.br/scielo.php?script=sci_arttext\&pid=S010279722012000200006\&lng=en\&nrm=i>. Acesso em: 12 mar. 2013.

RYLE, Gilbert. The concept of mind. Londres: Penguin Books, 2000.

SANTOS, Bettina Steren; DAVOGLIO, Tárcia Rita; SPAGNOLO, Carla. In: CONGRESSO INTERNACIONAL DE EDUCAÇÃO, 8., 2013, São Leopoldo, RS.; CONGRESSO

INTERNACIONAL DE AVALIAÇÃO, 3., 2013, São Leopoldo, RS. Anais... São Leopoldo, RS: Universidade do Vale do Rio dos Sinos, São Leopoldo. v.1., p. 2013-2015.

SELLTIZ, Claire; WRIGHTSMAN, Lawrence S.; COOK, Stuart W. Métodos de pesquisa nas relações sociais. São Paulo: Herder, 1972.

TODOROV, João Cláudio; MOREIRA, Márcio Borges. O conceito de motivação na psicologia. Revista Brasileira de Terapia Comportamental e Cognitiva, Curitiba, v. 7, n. 1, p. 119-132, 2005.

TORRECILLA, F. Javier Murillo. Avaliação do desempenho e carreira docente: um estudo em cinquenta países da América e Europa. In: BALZANO, S. (Org.). O desafio da profissionalização docente no Brasil e na América Latina. Brasília: CONSED; UNESCO, 2007. p. $21-31$

URBINA, Susana. Essentials of psychological testing. New York: Hoboken, 2004.

ZAMBON, Melissa Picchi; ROSE, Tânia Maria Santana de. Motivação de alunos do ensino fundamental: relações entre rendimento acadêmico, autoconceito, atribuições de causalidade e metas de realização. Educ. Pesqui., São Paulo, v. 38, n. 4, p. 965-980, out./dez. 2012. 
Tárcia Rita Davoglio; Bettina Steren dos Santos

Tárcia Rita Davoglio - Pontifícia Universidade Católica do Rio Grande do Sul Porto Alegre | RS | Brasil. Contato: tarciad@gmail.com

Bettina Steren dos Santos- Pontifícia Universidade Católica do Rio Grande do Sul Porto Alegre | RS | Brasil. Contato: bettina @ pucrs.br

Artigo recebido em 23 de novembro de 2017 e aprovado em 24 de novembro de 2017. 